\title{
Optimal Vigilance Level and Hiring Illegal Immigrants
}

\author{
Munirul H. Nabin, Pasquale M. Sgro \\ Department of Economics, Deakin University, Geelong, Australia \\ Email: munirul.nabin@deakin.edu.au,sgro@deakin.edu.au
}

How to cite this paper: Nabin, M.H. and Sgro, P.M. (2017) Optimal Vigilance Level and Hiring Illegal Immigrants. Theoretical Economics Letters, 7, 1-12.

http://dx.doi.org/10.4236/tel.2017.71001

Received: September 2, 2016

Accepted: December 9, 2016

Published: December 13, 2016

Copyright $\odot 2017$ by authors and Scientific Research Publishing Inc. This work is licensed under the Creative Commons Attribution International License (CC BY 4.0).

http://creativecommons.org/licenses/by/4.0/

(c) $\underset{\mathrm{EY}}{\text { (i) Open Access }}$

\begin{abstract}
This paper assumes a Ricardian Economy and analyzes migration of illegal unskilled workers in a model of Cournot Duopoly where firms are producing homogenous and non-traded goods, and hiring illegal immigrants. The focus is on the behaviours of firms and the implications for the output, prices and employment of domestic workers in that industry. A two-stage simultaneous move game is set up: In Stage 1, for a given technology and vigilance level, each individual firm will decide whether to hire illegal immigrants. In Stage 2, each firm will choose the Cournot output level. Using this structure, we provide additional insights as to why firms hire illegal workers and what motivates these firms in their hiring practices. Furthermore the presence of illegal immigrants may create more employment for domestic workers and a social planner can be strategic in choosing optimal level of vigilance as we have shown that multiple solutions for optimal vigilance are possible and also Pareto ranked.
\end{abstract}

\section{Keywords}

Illegal Immigrants, Vigilance, Cournot Competition, Welfare

\section{Introduction}

Illegal migrants are present in almost every developed as well as several underdeveloped countries. Examples include Canada, the European Union, India, Japan, South Africa and the USA. For example, in the United States, combined evidence from various sources suggests that there were at least 7 million unauthorized migrants at the time of the 2000 census, out of a total of 31 million foreign-born people in the country, who were not US citizens at the time of their birth. Of the unauthorized, an estimated 4.8 million were Mexican? [1] $]^{1}$. A more recent figure has confirmed that the total estimated number of illegal immigrants in the US has increased to 12 million [2].

${ }^{1}$ It can also be a very divisive issue in many countries as recent examples in France, UK and the USA show. 
Although the issue of whether illegal migrants enhance the welfare of a host country is debatable, most countries have adopted policies to halt the flow of illegal immigration [3] [4] [5]. Two common policies, which are used by most countries to halt the flow of illegal migrants, are (i) internal enforcement such as imposing sanctions on employers who hire illegal migrants that includes-a demand-side policy, and (ii) border enforcement-a supply-side policy. Note that the supply side immigration policy could also be influenced by the immigrant's self-selection mechanism [6].

Both of the above policies, employer sanction and border enforcement, along with the effects of illegal immigration have been extensively analyzed in the international trade literature [7] [8] [9] [10]. These analyses have generally taken place utilising perfectly competitive general equilibrium (hereafter GE) frameworks.

However, many industries that hire illegal migrants are operating under an oligopoly market structure. For example, The US meat-packer industry which predominantly hires illegal migrants operates under an oligopoly market structure where strategic interaction plays a crucial role [11]. The problem is so severe that one of the kosher meat-packing companies in Iowa, which had been charged for hiring illegal immigrants, and was fined so heavily that it filed for bankruptcy [12]. Recent evidence, as argued by Porter (2006), suggests that even though the US has declared an all-out war against illegal immigration by increasing the border enforcement budget, a closer examination reveals that the deterrent effect of the designed policy is small [13] [14] ${ }^{2}$. Porter (2006) has argued that one of the main reasons for the continued ineffectiveness of the illegal immigration policy (policing) is that the work-place is virtually unpoliced ${ }^{3}$. This is due, in part, to political pressure not to police the work-place as it hurts employers.

Therefore, to analyze such industries, one needs to utilize a partial equilibrium framework. Despite the limitation of such a framework (compared to GE), it may provide more insights into the behaviour of an individual firm that operates under an oligopoly market structure and hires illegal migrants. This also plays a crucial role in the design and implementation of the demand-side policy of employer sanction in such a market structure. Thus our focus is on the role of vigilance and employer sanctions rather than the relative effectiveness of boarder enforcement versus employer sanctions.

Our paper is organised as follows: Section 2 provides the basic model set-up, Section 3 analyses welfare and determines the optimal vigilance level and Section 4 concludes.

\section{Model}

\section{Preliminaries}

We utilise the same set-up as Nabin and Sgro (2013) and their Lemma 1 below and Lemma 2 in the next section 3.1 for our analysis. There are two firms, 1 and 2 , operating in a Ricardian Economy where the only means of production is unskilled labour ${ }^{4}$. Each individual firm is producing non-traded homogenous goods $q_{i}$, where

${ }^{2}[15]$ argues that illegal immigrants can also reduce their chances of being caught by hiring smugglers, who are often called coyotes.

${ }^{3}$ On the other hand, internal enforcement has proven very effective in northern European countries such as Germany and the Netherlands [16].

${ }^{4} \mathrm{We}$ are considering a very simple production structure. Other factors of production such as capital, could be added but will unnecessarily complicate the model. 
$i=\{1,2\}$. The market demand function is $P(Q)=A-Q$ where $Q$ is the total amount of output (i.e. $Q=\sum_{i=1}^{2} q_{i}$ ) produced by the two firms. An individual firm will maximize the following objective function:

$$
\max _{q_{i}} \Pi=\left[P(Q)-c_{i}\right] q_{i}
$$

Here, $c_{i}>0$ is the cost of producing one unit of output. Assume that, for given technology $T$, an individual firm $i$ needs $\hat{l}_{T}$ labour (assuming that $0 \leq \hat{l}_{T} \leq 1$ ) in order to produce one unit of output $q_{i}$ i.e. labour demand to produce one unit of output is $\hat{l}_{T}$. We assume linear production technology where the labour demand for unit output is fixed for a given technology $T^{5}$.

The unskilled labour market consists of both domestic denoted by $d$ and illegal immigrant workers, per unit of output denoted by $h$. It is also assumed that unskilled labour market is characterized by surplus labour and a binding minimum wage is in operation.

Each firm $i$ has to pay the minimum wage $\bar{w}>0$ per unit of domestic worker $d$. Therefore, the cost of hiring a domestic worker by an individual firm $i$ to produce one unit of output, denoted by $c_{i}^{d}$, is as follows:

$$
c_{i}^{d}=\bar{w}
$$

Alternatively, each individual firm can hire illegal migrants. The cost of hiring an illegal migrant $h$ depends on: (i) the minimum wage, denoted by $\theta \bar{w}$, paid to illegal migrant where the parameter $\theta \in(0,1]$. Without loss of generality, we assume that $\theta$ is given ${ }^{6}$. In the absence of vigilance and employer sanction, for any $\theta$ such that $\theta<1, h=\hat{l}_{T}$ and an individual firm has an incentive to hire illegal immigrants only. However, in the case where both vigilance and employer sanction are present, $h \neq \hat{l}_{T}$ and an individual firm has an incentive to hire both domestic and illegal workers such that $h \in\left[0, \hat{l}_{T}\right)$.

The expected punishment cost of hiring an illegal migrant is denoted by $p Z$. The parameter $Z(>\bar{w})$ is the punishment cost, or the employer sanction measured in monetary units, and $p$ is the probability of being caught for hiring illegal migrants. The probability $p$ depends on a given level of vigilance $v$, such that $v \in[0, \bar{v}]$, and the number of illegal migrants per unit of output $h$ (hired by an individual firm). Here, $\bar{v}$ is the highest level of vigilance. Let us consider $p=[\alpha[\phi(v) h]+(1-\alpha)]$. Here, $\alpha$ is the indicator parameter and $p$ satisfies the following assumption:

\section{Assumption 1}

A. $\alpha= \begin{cases}1 & \text { if } v \in[0, \bar{v}) \text { and } h<\hat{l}_{T}, \\ 0 & \text { if } v=\bar{v} \text { or } / \text { and } h=\hat{l}_{T} .\end{cases}$

B. $0 \leq \phi(v) h \leq 1$; and $\forall v \in[0, \bar{v}]$ the following is true: $\phi_{v}^{\prime}(v)>0$.

\footnotetext{
${ }^{5}$ Though the limitations of linear technology are known, this assumption can be justified by the historical evidence, at least in English agricultural production as found by [17]. Furthermore, this assumption also implies that domestic workers and illegal immigrants are perfect substitutes for each other.

${ }^{6}$ Alternatively, one can think that $\theta$ represents the level of exploitation of an illegal worker of an industry i.e. an industry with high moral has high value of $\theta$ hence less exploitation and vice versa. Each individual firm in that industry operates with this industry's level of $\theta$ because of competition.
} 
C. $\forall h>0, \phi(v) h \rightarrow 0$ as $v \rightarrow 0$; and $\forall v>0, \phi(v) h \rightarrow 0$ as $h \rightarrow 0$.

Assumption 1 implies that an individual firm's probability of being caught for hiring illegal immigrants depends on both the level of vigilance and the number of illegal immigrants hired. One might argue that both the type and number of illegal immigrants affect the probability of being caught. If the illegal immigrant is from the same ethnic group as the domestic worker, it is easier to blend into the workforce. On the other hand, if the illegal migrant looks different, it is much harder to blend in. For a given level of vigilance, the probability of being caught would be greater for the latter group than the former. The indicator parameter $\alpha$ incorporates this. If an individual firm hires all illegal immigrants from different ethnic backgrounds (i.e. $h=\hat{l}_{T}$ ) then probability of getting caught is 1 i.e. $p=1$. The probability of getting caught is also 1 if government chooses the highest level of vigilance ie $v=\bar{v}$.

Firm i's unit cost of hiring an illegal migrant, denoted by $c_{i}^{h}$, is as follows:

$$
c_{i}^{h}=\theta \bar{w}+\phi(v) h Z \text {. }
$$

An individual firm has an incentive to hire illegal immigrant if the following condition is met $^{7}$ :

$$
c_{i}^{h} \leq c_{i}^{d} \Rightarrow h \leq \frac{(1-\theta) \bar{w}}{\phi(v) Z} \equiv h^{*}
$$

One of the implications of Equation (4) is as follows: for any given $v>0$, the cost of hiring labour for producing one unit of output will be as follows ${ }^{8}$ :

$$
c_{i}= \begin{cases}\hat{c}_{T}^{d}=\bar{w} \hat{l}_{T} & \text { for } \hat{l}_{T} \leq h^{*}, \\ \hat{c}_{T}^{d h}=\bar{w}\left[\hat{l}_{T}-h^{*}(1-\theta)\right] & \text { for } \hat{l}_{T}>h^{*} .\end{cases}
$$

Indeed, the above expression reveals that there exists a non-monotonic relationship between the increased vigilance level and domestic job creations. Note that, If an individual firm chooses not to hire illegal migrants then the unit cost of hiring labour will be $c_{i}=\hat{c}_{0}=\bar{w} \hat{l}_{T}$.

Structure of the Game: In this game, an individual firm's decision is taken in two stages:

Stage 1: In this stage, an individual firm will decide whether to hire illegal immigrants.

Stage 2: An individual firm will then choose its output level $q_{i}$, i.e., each firm is engaging in Cournot-Nash Competition.

The above game can be solved by backward induction. One can easily solve Stage 2 of this game. Since each firm is facing Cournot-Nash Competition, one obtains the following standard Cournot results by using Equation (1):

${ }^{7}$ Note that the total cost minimization problem of hiring labour per unit of output will be as follows: $\min _{\{h\}}=[\theta \bar{w}+\phi(v) h] h+\left[\hat{l}_{T}-h\right] \bar{w} \Rightarrow h=\frac{(1-\theta) \bar{w}}{2 \phi(v) Z} \equiv \hat{h}^{*+*}$. However, an individual firm finds it profitable to hire more illegal immigrants $h$ as long as any $h \leq h^{*}$. Since $\hat{h}^{* *}<h^{*}$, the only binding condition will be $h^{*}$.

${ }^{8}$ For more details, please see [18]. 


$$
\begin{aligned}
q_{1}^{*}\left(c_{1}, c_{2}\right) & =\frac{1}{3}\left[A-2 c_{1}+c_{2}\right] \text { and } \Pi_{1}^{*}=\left[q_{1}^{*}\left(c_{1}, c_{2}\right)\right]^{2} \\
q_{2}^{*}\left(c_{1}, c_{2}\right) & =\frac{1}{3}\left[A-2 c_{2}+c_{1}\right] \text { and } \Pi_{2}^{*}=\left[q_{2}^{*}\left(c_{1}, c_{2}\right)\right]^{2} \\
P^{*} & =A-q_{1}^{*}\left(c_{1}, c_{2}\right)-q_{2}^{*}\left(c_{1}, c_{2}\right) \\
C S\left(c_{1}, c_{2}\right) & =\frac{1}{2}\left\{\left[q_{1}^{*}\left(c_{1}, c_{2}\right)\right]^{2}+\left[q_{2}^{*}\left(c_{1}, c_{2}\right)\right]^{2}\right\}+q_{1}^{*}\left(c_{1}, c_{2}\right) q_{2}^{*}\left(c_{1}, c_{2}\right) \\
P S\left(c_{1}, c_{2}\right) & =\left[q_{1}^{*}\left(c_{1}, c_{2}\right)\right]^{2}+\left[q_{2}^{*}\left(c_{1}, c_{2}\right)\right]^{2} \\
W\left(c_{1}, c_{2}\right) & =\frac{3}{2}\left\{\left[q_{1}^{*}\left(c_{1}, c_{2}\right)\right]^{2}+\left[q_{2}^{*}\left(c_{1}, c_{2}\right)\right]^{2}\right\}+q_{1}^{*}\left(c_{1}, c_{2}\right) q_{2}^{*}\left(c_{1}, c_{2}\right) \\
W\left(c_{1}, c_{2} \mid c_{1}=c_{2}\right) & =\left[q_{1}^{*}\left(c_{1}, c_{2} \mid c_{1}=c_{2}\right)+q_{2}^{*}\left(c_{1}, c_{2} \mid c_{1}=c_{2}\right)\right]^{2}
\end{aligned}
$$

where the "*" signifies the equilibrium values and CS, $P S$ and $W$ stand for consumer surplus, producer surplus and welfare, respectively, $W=C S+P S$ at equilibrium.

An individual firm $i$ will find that hiring illegal immigrants reduces the value of $c_{i}$ because they are paid less than the domestic workers ${ }^{9}$. In this case, solving Stage 1 of this game, involves a Nash equilibrium where each firm hires illegal migrants. However, in the presence of interior vigilance level $v$, the above result may not hold. Therefore, one needs to characterize the role of $v$ in determining the value of $c_{i}$. This is crucial not only for solving the Stage 1 of our game, but also to the understanding of how firms behave when they are hiring illegal immigrants. Indeed, Nabin and Sgro (2013) have developed the following Lemma :

Lemma 1. For any given technology such that $\forall \hat{l}_{T}>h^{*}$, an individual firm finds the strategy of hiring illegal immigrants profitable at equilibrium and such a strategy is also dominant over the strategy of not hiring illegal immigrants. However, if $\hat{l}_{T} \leq h^{*}$ then no individual firm is hiring illegal immigrants.

Proof. See Nabin and Sgro (2013) for proof [18].

For given technology $T$ and $\forall \hat{l}_{T}>h^{*}$, one can also derive the total demand for illegal immigrants which is as follows:

$$
E_{d}^{h}=h^{*} Q^{*}=h^{*} \frac{2}{3}\left[A-\hat{l}_{T}+h^{*}(1-\theta)\right]
$$

where $h^{*}$ is the demand for an illegal immigrant to produce one unit of output, and $Q^{*}$ is the aggregate level of output of a given industry.

\section{Analysis}

\subsection{Welfare Analysis}

Conditions for an individual firm hiring both domestic workers and illegal immigrants, or hiring only domestic workers have been derived (i.e. Lemma 2). To complete our analysis we need to analyze the welfare of an industry when an individual firm has an incentive to hire illegal immigrants for a given technology. Without loss of generality and to keep our analysis simple, we normalize $\bar{w}=1$, this also implies that $Z>1$ (this follows from our earlier discussion).

${ }^{9}$ Illegal immigrants have less market power because of their illegal status. 
This section considers two welfare criteria to analyze the welfare of an industry. Our concern is not about social welfare both the effects on certain industries with imperfectly competitive market structures.

Criterion 1: This criterion simply considers Marshallian surplus to examine the welfare of the given industry. For a given technology $T$, if no one hires illegal immigrants, the total surplus will be as follows (from Equation (5)):

$$
W_{0}^{T}=\frac{4}{9}\left[A-\hat{l}_{T}\right]^{2}
$$

Similarly, for given technology $T$, if an individual firm hires illegal immigrants, the total surplus will be as follows:

$$
W_{h}^{T}= \begin{cases}\frac{4}{9}\left[A-\hat{l}_{T}+h^{*}(1-\theta)\right]^{2} & \forall \hat{l}_{T}>h^{*} \\ \frac{4}{9}\left[A-\hat{l}_{T}\right]^{2} & \forall \hat{l}_{T} \leq h^{*}\end{cases}
$$

Criterion 2: Our second criterion emphasizes the employment level of domestic workers. For given technology $T$, if no one hires illegal migrants, total employment for domestic unskilled workers, in this particular industry, will be as follows (from Equation (5)):

$$
E_{0}^{T}=\hat{l}_{T} \sum_{i=1}^{2} q_{i}^{*}=\hat{l}_{T} \frac{2}{3}\left[A-\hat{l}_{T}\right]
$$

Similarly, for given technology $T$, if an individual firm hires illegal migrants, total employment for domestic unskilled workers, in this particular industry, will be as follows :

$$
E_{h}^{T}= \begin{cases}\left(\hat{l}_{T}-h^{*}\right) \frac{2}{3}\left[A-\hat{l}_{T}+h^{*}(1-\theta)\right], & \forall \hat{l}_{T}>h^{*} \\ \hat{l}_{T} \frac{2}{3}\left[A-\hat{l}_{T}\right], & \forall \hat{l}_{T} \leq h^{*}\end{cases}
$$

By using the Equations (6), (7), (8) and (9), we develop the following proposition:

Proposition 1. $\forall \theta \in(0,1]$, the following will be true for a given industry.

A. Given technology $\hat{l}_{T}$ such that if $\hat{l}_{T}>h^{*}$, then hiring illegal migrants is welfare enhancing as $W_{h}^{T} \geq W_{0}^{T}$.

B. (i) $\forall \hat{l}_{T}>h^{*}$ and $\hat{l}_{T}<A \leq \frac{2 \hat{l}_{T} \phi(v) Z-1}{\phi(v) Z}, \exists \theta^{*}$ such that $\theta<\theta^{*}$ then $E_{h}^{T} \geq E_{0}^{T}$ and if $\theta>\theta^{*}$ then $E_{h}^{T}<E_{0}^{T}$.

(ii) However, $\forall \hat{l}_{T}>h^{*}$ and $A>\frac{2 \hat{l}_{T} \phi(v) Z-1}{\phi(v) Z}$, then $E_{h}^{T}<E_{0}^{T}$.

C. If $\hat{l}_{T} \leq h^{*}$ then $W_{h}^{T}=W_{0}^{T}$ and $E_{h}^{T}=E_{0}^{T} \quad$ will be true.

Proof. Please see the Appendix.

The above proposition tells us that, contrary to conventional wisdom, hiring illegal immigrants is not necessarily detrimental to welfare or domestic job creation for domestic workers in a given industry. Figure 1 illustrates Propositions $1 \mathrm{~A}$ and $1 \mathrm{~B}(\mathrm{i})$ for the parameter values $A=0.59, \hat{l}_{T}=0.5, \phi(v) Z=3$ and $\forall \theta \in[0,1]$. In Figure 1, (a) illustrates the welfare of an economy, whereas (b) illustrates the domestic job creation in a given industry. Clearly, when $\theta<0.8$ and each firm is hiring illegal 


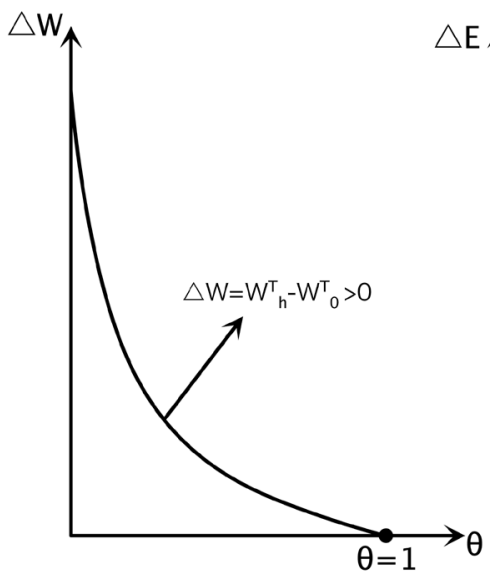

(a)

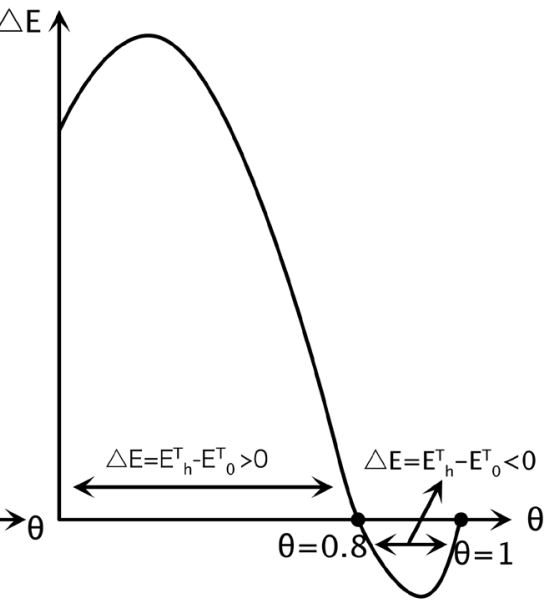

(b)

Figure 1. (a) Welfare of an industry and (b) Domestic Job Creation.

immigrants, employment opportunities for domestic workers are higher than when no firm hires illegal immigrants. Given the production technology, for a lower value of $\theta$, a firm is able to hire more illegal immigrants only by hiring more domestic workers. This follows from the non-monotonic unit cost of production. The fact is that, in the presence of vigilance and employer sanction and for any $\theta$ such that $\theta<1$, both illegal workers and domestic workers become complementary factors ${ }^{10}$. Therefore, it is interesting to analyze the role of vigilance level and firms' hiring behaviour regarding domestic workers.

Our result is consistent with the earlier empirical findings of [19] where they used the Leontief production function to estimate the effect of illegal Mexican immigrants on native workers.

\subsection{Optimal Vigilance Level}

To understand the effect of an increased vigilance level on employment opportunities of native workers, we rewrite Equation (9) as follows:

$$
E_{h}^{T}=a^{d} Q^{*} \quad \forall \hat{l}_{T}>h^{*} \text { where } a^{d}=\hat{l}-h^{*} \text { and } Q^{*}=\frac{2}{3}\left[A-\hat{l}_{T}+h^{*}(1-\theta)\right]
$$

By differentiating Equation (10) with respect to $v$ we get:

$$
\begin{aligned}
\frac{\Delta E_{h}^{T}}{\Delta v} & =\frac{\Delta a^{d}}{\Delta v} Q^{*}+\frac{\Delta Q^{*}}{\Delta v} a^{d} \\
& \left.\Rightarrow \frac{\Delta E_{h}^{T} \cdot v}{\Delta v \cdot E_{h}^{T}}=\frac{\Delta a^{d} \cdot v}{\Delta v \cdot E_{h}^{T}} Q^{*}+\frac{\Delta Q^{*} \cdot v}{\Delta v \cdot E_{h}^{T}} a^{d} \quad \text { (divide both side by } \frac{v}{E_{h}^{T}}\right) \\
& \Rightarrow \frac{\Delta E_{h}^{T} \cdot v}{\Delta v \cdot E_{h}^{T}}=\frac{\Delta a^{d} \cdot v}{\Delta v \cdot a^{d}}+\frac{\Delta Q^{*} \cdot v}{\Delta v \cdot Q^{*}} \quad \text { (follows from Equation (10)) } \\
& \Rightarrow \eta_{E_{h}^{T}, v}=\eta_{a^{d}, v}-\left|\eta_{Q^{*}, v}\right|
\end{aligned}
$$

${ }^{10}$ Note that $E_{h}^{T}=a^{d} Q^{*}$, where $a^{d}=\hat{l}-h^{*}$ and $Q^{*}=\frac{2}{3}\left[A-\hat{l}_{T}+h^{*}(1-\theta)\right]$. A lower value of $\theta$ will increase $Q^{*}$ but reduce $a^{d}$ and, if the effect of an increased $Q^{*}$ is dominant over the effect of reduced $a^{d}$, it will lead to an outcome where more jobs are created for native workers. 
Here, $\eta_{E_{h}^{T, v}}=\frac{\Delta E_{h}^{T} \cdot v}{\Delta v \cdot E_{h}^{T}}, \quad \eta_{a^{d}, v}=\frac{\Delta a^{d} \cdot v}{\Delta v \cdot a^{d}}>0$ and $\eta_{Q^{*}, v}=\frac{\Delta Q^{*} \cdot v}{\Delta v \cdot Q^{*}}<0$.

Equation (11) helps us to develop the following proposition:

Proposition 2. For given technology $T$ and $\forall \hat{l}_{T}>h^{*}$, the following will be true:

A. If $\eta_{a^{d}, v}>\left|\eta_{Q^{*}, v}\right|$ then $\eta_{E_{h}^{T}, v}>0$.

B. If $\eta_{a^{d}, v}=\left|\eta_{Q^{*}, v}\right|$ then $\eta_{E_{h}^{T}, v}=0$.

C. If $\eta_{a^{d}, v}<\left|\eta_{Q^{*}, v}\right|$ then $\eta_{E_{h}^{T}, v}<0$.

Proof. The proof mainly follows from Equation (11).

Proposition 2 states that an increase in the vigilance level will not necessarily lead to an increase in employment opportunities for native workers. Indeed, there is a nonmonotonic relationship between the vigilance level and employment of native workers. An increase in the vigilance level has two effects: (i) it will reduce the value of $h^{*}$, and increase the value of $a^{d}$. This occurs because an increase in the vigilance level will increase the cost of hiring illegal migrants to produce one unit of output, hence a firm has less incentive to hire illegal immigrants; and (ii) it will reduce the aggregate output level, $Q^{*}$. Since total employment for native workers is also proportional to aggregate output level, it will also fall. Clearly, these two effects are moving in opposite directions. Therefore, the total employment opportunities for native workers due to increased vigilance, depend on which effect will dominate. Indeed, Proposition 2 explains this in terms of the elasticities of total employment (for native workers), $E_{h}^{T}, a^{d}$ and aggregate output level $Q^{*}$ with respect to $v$. Figure 2 illustrates these two effects more clearly.

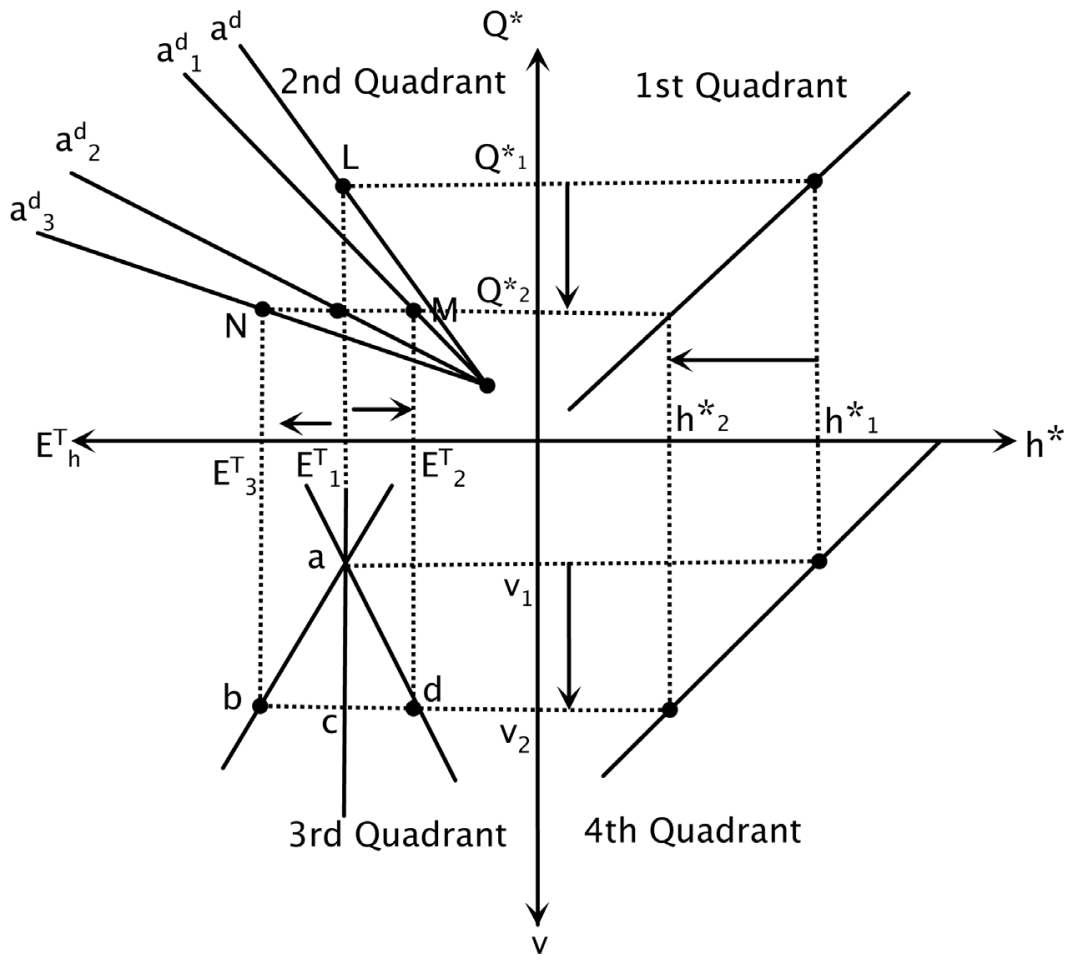

Figure 2. Employment opportunities for native workers and vigilance level. 
Figure 2 illustrates the relationship between the vigilance level $v$ and employment for native workers $E_{h}^{T}$ using a four quadrants diagram. The fourth quadrant illustrates the negative relationship between $v$ and $h^{*}$ (from condition (4)), the first and second quadrants illustrate the positive relationship between: (i) $h^{*}$ and $Q^{*}$ (from Equation (10)) (ii) $Q^{*}$ and $E_{h}^{T}$ (from Equation (10)) respectively. Finally, the third quadrant illustrates the non-monotonic relationship between $E_{h}^{T}$ and $v$ (from Proposition 2). For a given level of vigilance level $v_{1}$, the corresponding $h^{*}$ will be $h_{1}^{*}$ as shown in the fourth quadrant. Thus $h_{1}^{*}$ will lead us to output level $Q_{1}^{*}$, which is shown in the first quadrant. Given $a^{d}$, this $Q_{1}^{*}$ leads us to employment level $E_{1}^{T}$ shown in the second quadrant. In the third quadrant, $E_{1}^{T}$ translates to vigilance level $v_{1}$ which is shown as $a$. Suppose $v_{1}$ increases to $v_{2}$, as a result $h_{1}^{*}$ falls to $h_{2}^{*}$ (shown in the fourth quadrant) which eventually reduces aggregate output level $Q_{1}^{*}$ to $Q_{2}^{*}$ (shown in the first quadrant). Furthermore, a decrease in $h^{*}$ from $h_{1}^{*}$ to $h_{2}^{*}$ --will also increase the value of $a^{d}$ to either $a_{1}^{d}$ or $a_{2}^{d}$ or $a_{3}^{d}$ (shown in the second quadrant) and this effect, along with falling output level, will lead to either a decrease in total employment to $E_{2}^{T}$, or no change in $E_{1}^{T}$ or an increase in total employment $E_{3}^{T} \quad$ (from Proposition 2) ${ }^{11}$.

The crucial point of the above diagram is that an increase in the vigilance level will not necessarily increase the total employment of native workers. Indeed, it might reduce the total employment for native workers because of the non-monotonic relationship between the vigilance level and the employment level for native workers (from our Proposition 2). The non-monotonic relationship also raises the possibility of the existence of $v^{*}$ such that it will maximize the employment opportunities for native workers. The following equation confirms this:

$$
\max _{v} E_{h}^{T}=a^{d} \cdot Q^{*} \Rightarrow v^{*} \Leftrightarrow \eta_{a^{d}, v}=\left|\eta_{Q^{*}, v}\right|
$$

The condition (12) leads to the following proposition:

Lemma 2. Multiple solutions for $v^{*}$ are possible. The following summarizes the result $t^{2}$ :

A. There exists a corner solution where $v^{*}=\bar{v}$.

B. $\forall \theta \in(0,1)$ and $\hat{l}_{T}<A<2 \hat{l}_{T}-\left(\frac{2(1-\theta)^{2}}{\phi(\bar{v}) Z}+\theta \hat{l}_{T}\right)$, there also exists an interior solution for $v^{*}$ such that $v^{*}=\phi^{-1}\left(\frac{2(1-\theta)^{2} \bar{w}}{Z\left[\hat{l}_{T}(2-\theta)-A\right]}\right) \equiv v^{* * *}<\bar{v}$.

\section{Proof. Please see the Appendix}

The above Lemma implies that if an individual social planner has an objective to maximize job opportunities for native workers then either she can choose $\bar{v}$ or $v^{* *}$,

${ }^{11}$ Our findings are consistent with the empirical evidence of [20] and the simulation work of [21] where they find that hiring more illegal immigrants may lead to more domestic job creations.

${ }^{12} \mathrm{We}$ assume that inverse of $\phi(v)$ exists and these multiple solutions must satisfy the second order condi-

$$
\begin{aligned}
\text { tion }(\forall \theta \in(0,1)): & \frac{\mathrm{d}^{2} E_{h}^{T}}{\mathrm{~d} v^{2}}=-\frac{2(1-\theta)}{3[\phi(v)]^{2} Z} \phi^{\prime}(v)\left[\frac{\phi^{\prime}(v) 2(1-\theta)^{2}}{[\varphi(v)]^{2} Z}(2+\theta)\right]-\frac{(1-\theta)^{2}}{[\phi(v)]^{2} Z}\left(\phi^{\prime}(v)-\phi^{\prime \prime}(v)\right)<0, \\
& \text { which is true as long as } \phi^{\prime \prime}(v) \leq 0 \text { or }\left(\phi^{\prime}(v)-\phi^{\prime \prime}(v)\right)>0 \text { holds. }
\end{aligned}
$$


where the former is the vigilance level for zero tolerance of illegal migrants and the latter the vigilance level that allows some illegal migrants. However, the vigilance level $v^{* *}$ is Pareto dominant over $\bar{v}$. Even though both levels of vigilance maximize the job opportunities for native workers, it is the latter which gives us relatively more welfare (from Proposition $1 \mathrm{~A}$ ). Thus our model suggests that there exists two sets of policies regarding the optimal vigilance level and these are $K_{1}=\left\{\bar{v}, W_{L}\right\}$ and $K_{2}=\left\{v * W_{H}\right\}$; where $\bar{v}>v^{* *}$ and $W_{L}<W_{H}$; and $K_{2}$ is Pareto dominant over $K_{1}$.

\section{Conclusion}

In this paper a Ricardian model has been used to examine the effects of illegal immigrants on firms in a Cournot Oligopoly model. A game theory framework has been used and internal vigilance has been analyzed as a policy to curb illegal immigrants. We have provided additional insights as to why firms hire illegal workers and what motivates these firms in their hiring practices. Furthermore, we have demonstrated that multiple solutions exist for the optimal level of vigilance. There exists a vigilance level with non-zero tolerance of illegal immigrants which is as effective, in creating industry employment opportunities for native workers, as the vigilance level with zero tolerance of illegal immigration. Finally, we have introduced a voting model to show which level of vigilance will be chosen.

\section{Acknowledgements}

We thank the editor and the referee for their comments.

\section{References}

[1] The California Farm Labor Force: Overview and Trends. National Agricultural Workers Survey (2003-2004). US Department of Labor, 2004.

[2] Knowledge@Wharton. On the Fence: Are Illegal Immigrants Good or Bad for the US Economy? 2007. http://knowledge.wharton.upenn.edu/article.cfm?articleid=1754

[3] Bhagwati. J.N. (1998) Comment on Borjas Michigan University Conference, Washington DC.

[4] Borjas. G.J. (1995) The Economic Benefits from Immigration. Journal of Economic Perspectives, 9, 3-22. https://doi.org/10.1257/jep.9.2.3

[5] Borjas, G.J. and Katz, L.F. (2005) The Evolution of the Mexican Born Workforce in the United States. NBER Working Paper, No. 11281.

[6] Bianchi, M. (2013) Immigration Policy and Self-Selecting Migrants. Journal of Public Economic Theory, 15, 1-23. https://doi.org/10.1111/jpet.12007

[7] Bhagwati, J.N. (1982) Directly Unproductive, Profit-Seeking (DUP) Activities. Journal of Political Economy, 90, 988-1002. https://doi.org/10.1086/261104

[8] Bond, E. and Chen, T-J. (1987) The Welfare Effects of Illegal Immigration. Journal of International Economics, 23, 315-328. https://doi.org/10.1016/0022-1996(87)90058-4

[9] Djajic, S. (1999) Dynamics of Immigration Control. Journal of Population Economics, 12, 45-61. https://doi.org/10.1007/s001480050090

[10] Ethier, W. (1986) Illegal Immigration: The Host-Country Problem. American Economic Review, 76, 56-71.

[11] Dyer, J. (2006) Meatpacking Industry Has a Long History of Reliance on Immigrant Labor- 
ers. The Fort Collins Weekly, 1-5.

[12] Preston, J. (2008) Large Iowa Meatpacker in Illegal Immigrant Raid Files for Bankruptcy. The New York Times. http://www.nytimes.com/2008/11/06/us/06immig.html

[13] Hanson, G. (2006) Illegal Migration from Mexico to the United States. Journal of Economic Literature, 44, 869-924. https://doi.org/10.1257/jel.44.4.869

[14] Porter, E. (2006) The Search for Illegal Immigrants Stops at the Workplace. The New York Times. http://www.nytimes.com/2006/03/05/business/yourmoney/05view.html

[15] Gathmann, C. (2006) Effects of Enforcement on Illegal Markets: Evidence from Migrants Smuggling along the Southwestern Border. Journal of Public Economics, 92, 1926-1941. https://doi.org/10.1016/j.jpubeco.2008.04.006

[16] Broeders, D. and Engberson, G. (2007) The Fight against Illegal Migration: Identification Policies and Immigrants' Counter-Strategies. American Behavioral Scientist, 50, 1592-1609. https://doi.org/10.1177/0002764207302470

[17] Clark, G. (1991) Yields per Acre in English Agriculture, 1250-1860: Evidence from Labour Inputs. The Economic History Review, 44, 445-460. https://doi.org/10.2307/2597538

[18] Nabin, M.H. and Sgro, P.M. (2013) Illegal Immigration, Technology Adoption and Welfare. Asia-Pacific Journal of Accounting and Economics, 20, 183-198. https://doi.org/10.1080/16081625.2012.738803

[19] Bean, F.D., Lowell, B.L. and Taylor, L.J. (1988) Undocumented Mexican Immigrants and the Earnings of Other Workers in the United States. Demography, 25, 35-52. https://doi.org/10.2307/2061476

[20] Passel, J.S. and Cohn, D. (2009) A Portrait of Unauthorized Immigrants in the United States. Report, Pew Hispanic Center, Washington DC.

[21] Grossman, J.B. (1984) Illegal Immigrants and Domestic Employment. Industrial and Labor Relations Review, 37, 240-251. https://doi.org/10.1177/001979398403700206 


\section{Appendix}

\section{Proof of Proposition 1}

(A) If $\hat{l}_{T}>h^{*}$ then from Equations (6) and (7), one can show that $W_{h}^{T} \geq W_{0}^{T}$ as long as $h^{*}(1-\theta) \geq 0$, which is true for all $\theta \in(0,1]$. (B) From Equations (8) and (9) one can calculate $\Delta E=E_{h}^{T}-E_{0}^{T}$. By putting $\Delta E=0$, one can solve for $\theta$ and the solution is: $\theta=\{1\},\left\{1-\frac{1}{2} \hat{l}_{T} \phi(v) Z+\frac{1}{2} \sqrt{4 \hat{l}_{T} \phi(v) Z+\left(\hat{l}_{T} \phi(v) Z\right)^{2}-4 A \phi(v) Z}\right\}$. Since $\left.\frac{\mathrm{d} \Delta E}{\mathrm{~d} \theta}\right|_{\theta=1}=\frac{2}{3 \phi(v) Z}\left(A-\hat{l}_{T}\right)>0$, this implies that at $\theta=1, \Delta E$ cuts the horizontal axis from below. Therefore, at other feasible solutions of $\theta, \Delta E$ must cut the horizontal axis from above. Then denote this $\theta$ as $\theta^{*}$. This implies that for any $\theta$ such that $\theta<\theta^{*}, \Delta E>0 \Rightarrow E_{h}^{T}>E_{0}^{T}$. For feasibility of such $\theta^{*}=1-\frac{1}{2} \hat{l}_{T} \phi(v) Z+\frac{1}{2} \sqrt{4 \hat{l}_{T} \phi(v) Z+\left(\hat{l}_{T} \phi(v) Z\right)^{2}-4 A \phi(v) Z}$, it must lie between 0 and 1 . This gives us the condition: $\hat{l}_{T}<A \leq \frac{2 \hat{l}_{T} \phi(v) Z-1}{\phi(v) Z}$. Therefore, if $A>\frac{2 \hat{l}_{T} \phi(v) Z-1}{\phi(v) Z}$, then the only feasible solution for $\theta$ will be 1 . Since $\Delta E$ cuts the horizontal axis from below at $\theta=1$, therefore, in this case $\Delta E<0 \Rightarrow E_{h}^{T}<E_{0}^{T}$. (C) This proof follows mainly from Lemma 2. Lemma 2 states that no firm will hire illegal migrants if $\hat{l}_{T} \leq h^{*}$. Therefore, in the presence of illegal migrants, $W_{h}^{T}=W_{0}^{T}$ and $E_{h}^{T}=E_{0}^{T}$.

\section{Proof of Lemma 2}

(A) From condition (12) and with the help of Equation (10), one can explicitly solve for $v^{*}$, which is as follows:

$$
\phi\left(v^{*}\right)=\frac{2(1-\theta)^{2}}{Z\left[\hat{l}_{T}(2-\theta)-A\right]} \Rightarrow v^{*}=\phi^{-1}\left(\frac{2(1-\theta)^{2} \bar{w}}{Z\left[\hat{l}_{T}(2-\theta)-A\right]}\right)
$$

For feasibility of $v^{*}$, we need the condition $0<v^{*}<\bar{v}_{h}$ be satisfied. This requires $\theta<1$ (which is true by our assumption), $\hat{l}_{T}<A<2 \hat{l}_{T}-\theta \hat{l}_{T}$ and $\hat{l}_{T}<A<2 \hat{l}_{T}-\left(\frac{2(1-\theta)^{2}}{\phi(\bar{v}) Z}+\theta \hat{l}_{T}\right)$. Here, the binding condition is $\hat{l}_{T}<A<2 \hat{l}_{T}-\left(\frac{2(1-\theta)^{2}}{\phi(\bar{v}) Z}+\theta \hat{l}_{T}\right)$.

(B) Assumption 1 tells us that if $v=\bar{v}$ then $p=1$. This implies that if $v=\bar{v}$ then $h^{*}=0$. If so then $v=\bar{v}$ implies that $\eta_{a^{d}, v}=\left|\eta_{Q^{*}, v}\right|=0$ (follows from Equation (10)). Therefore, $v^{*}=\bar{v}$ satisfies condition 12 . 
Submit or recommend next manuscript to SCIRP and we will provide best service for you:

Accepting pre-submission inquiries through Email, Facebook, LinkedIn, Twitter, etc. A wide selection of journals (inclusive of 9 subjects, more than 200 journals) Providing 24-hour high-quality service

User-friendly online submission system

Fair and swift peer-review system

Efficient typesetting and proofreading procedure

Display of the result of downloads and visits, as well as the number of cited articles Maximum dissemination of your research work

Submit your manuscript at: http://papersubmission.scirp.org/

Or contact tel@scirp.org 